\title{
ESTIMASI DAYA DUKUNG LINGKUNGAN KERAMBA JARING APUNG, DI PERAIRAN PULAU SEMAK DAUN KEPULAUAN SERIBU, DKI JAKARTA
}

\author{
THE ESTIMATION CARRYING CAPACITY OF AQUATIC ENVIRONMENT FLOATING \\ NET CAGE ON SEMAK DAUN ISLAND, SERIBU ISLANDS, JAKARTA CITY
}

\author{
Aditya Bramana ${ }^{1}$, Ario Damar ${ }^{2}$, Rahmat Kurnia ${ }^{2}$ \\ ${ }^{1}$ Departemen Manajemen Sumberdaya Perairan \\ ${ }^{2}$ Departemen Manajemen Sumberdaya Perairan \\ Fakultas Perikanan dan Kelautan, Institut Pertanian Bogor \\ Korespondensi : umsiniputra@yahoo.com
}

\begin{abstract}
This research describing about the estimation of carrying capacity of water environment against cultivation activities, whereas the type of fish that has been cultivated was grouper fish. Organic waste estimation and carrying capacity of water environment prediction were used to analyze this research. This research resulting that waste loads from cultivation activities were equal to $1.04 \mathrm{~kg} \mathrm{~N} /$ day/ unit and the estimation of anthropogenic waste loads were $20.56 \mathrm{~kg}$ $\mathrm{N} /$ day. Based on approach of waste loads N, carrying capacity of water environment of Semak Daun Island against cultivation activities is 114 units of floating net cages. Assumed a unit of floating net produce of $300 \mathrm{~kg}$ of fish, it acquired 28.20 tonnes of fish production can was accommodated
\end{abstract}

Keywords: carrying capacity, grouper, Semak Daun Island

\begin{abstract}
ABSTRAK
Penelitian ini menguraikan estimasi daya dukung lingkungan perairan terhadap kegiatan budidaya.Analisis yang digunakan yaitu estimasi limbah organik dan pendugaan daya dukung perairan. Jenis ikan yang dibudidayakan yaitu ikan kerapu. Hasil penelitian menunjukkan, bahwa beban limbah dari kegiatan budidaya sebesar $1.04 \mathrm{~kg} \mathrm{~N} / \mathrm{hari} /$ unit. Estimasi beban limbah antropogenik yaitu $20.56 \mathrm{~kg} \mathrm{~N} /$ hari. Berdasarkan pendekatan beban limbah N, daya dukung lingkungan perairan Pulau Semak Daun terhadap kegiatan budidaya adalah 114 unit keramba jaring apung. Diasumsikan satu unit keramba jaring apung menghasilkan $300 \mathrm{~kg}$ ikan, maka diperoleh 28.2 ton produksi ikan yang dapat ditampung.
\end{abstract}

Kata kunci: ikan kerapu, daya dukung, Pulau Semak Daun

\section{PENDAHULUAN}

Kawasan Kepulauan Seribu, sekitar 70 penduduknya menggantungkan hidupnya pada perairan laut Kepulauan Seribu. Sebanyak 21-40\% merupakan nelayan tangkap yang melakukan penangkapan di sekitar ekosistem terumbu karang. Sekitar 69\%-92\% nelayan dari lima kelurahan (Pulau Panggang, Pulau Kelapa, Pulau Pari, Pulau Harapan dan Pulau Untung Jawa) mengatakn bahwa hasil tangkapan mengalami penurunan (Napitupulu 2005). Pemanfaatan sumberdaya perairan laut di kawasan Kepulauan Seribu yang dilakukan tidak terencana dan pengawasan yang kurang baik menyebabkan kondisi stok ikan mengalami kondisi tangkap lebih (overfishing), degradasi sumberdaya alam akibat pencemaran, penangkapan ikan dengan menggunakan bom dan bahan kimia, pengambilan karang yang berlebihan dan lain-lain. Kondisi seperti ini yang menyebabkan sebagian besar penduduk akan terperangkap dalam kemiskinan akibat produktivitas sumberdaya yang semakin berkurang dan terjadinya kerusakan lingkungan (Rudiyanto 2011).

Fenomena penurunan produksi tangkapan dan degradasi habitat telah menimbulkan kekhawatiran masyarakat akan terjadinya kelangkaan sumberdaya ikan. Merespons dari kondisi yang terjadi, Pemerintah Kabupaten Administrasi 
Kepulauan Seribu sejak tahun 2004 mencoba mengembangkan perpaduan antara kegiatan budidaya laut dengan perikanan tangkap yang berdasarkan kepada konseps sea farming (PKSPL 2006).

Kegiatan sea farming yang dilakukan di daerah perairan Kepulauan Seribu atau tepatnya di perairan Pulau Semak Daun terdapat beberapa kegiatan utama didalamnya, yaitu budidaya ikan (pembenihan dan pembesaran), restocking sumberdaya ikan, aktivitas wisata bahari, dan rehabilitasi terhadap sumberdaya perikanan dan lingkungan laut. Saat ini kegiatan yang sudah dilakukan yaitu budidaya ikan, termasuk di dalamnya kegiatan pembenihan dan pembesaran.

Budidaya perikanan merupakan salah satu bentukkegiatan pemanfaatan sumberdaya yang dapat dijadikan sebagai alternatif dalam meningkatkan taraf hidup masyarakat. Oleh karena itu, dalam perencanaan pembangunan pada suatu ekosistem pesisir atau laut yang berimplikasi kepada perencanaan pemanfaatan sumberdaya alam, perlu diperhatikan kaidah-kaidah ekologis yang berlaku dalam mengurangi dampak negatif bagi kelangsungan pembangunan (Bengen 2001). Perikanan budidaya dipercaya banyak orang akan berperan dalam memenuhi permintaan perikanan sebagai pengganti dari semakin sulitnya perikanan tangkap (Tacon 2003).

Aktivitas keramba jaring apung atau kegiatan budidaya perikanan di perairan Semak Daun memiliki potensi mengganggu ekosistem perairan yang disebabkan dari limbah pakan ikan. Pakan ikan yang diberikan tidak akan habis dikonsumsi oleh ikan dan meninggalkan sisa bahan organik. Limbah bahan organik dari kegiatan budidaya keramba jaring apung yang tidak terkendali dengan baik akan menyebabkan terjadinya eutrofikasi atau pengkayaan perairan dari unsur nitrogen dan fosfat sehingga dapat mengganggu kegiatan keramba jaring apung itu sendiri. Oleh karena itu, dalam memanfaatkan dan mengelola sumber daya kelautan dan perikanan perlu diperhatikan daya dukung lingkungan perairan. Salah satu cara yang digunakan dalam pengembangan kegiatan keramba jaring apung yaitu dengan melihat dampak masukan bahan organik dari sisa pakan kegiatan keramba jaring apung serta kegiatan antropogenik di sekitarnya untuk pemanfaatan dan pengelolaan sumber daya perikanan yang berkelanjutan. Penelitian ini untuk mengurangkan daya dukung lingkungan terhadap kegiatan budidaya di Perairan Pulau Semak Daun berdasarkan penghitungan beban limbah $\mathrm{N}$.

\section{METODE PENELITIAN}

Penelitian ini dilakukan di wilayah perairan Pulau Semak Daun, yang terletak di Kepulauan Seribu, DKI Jakarta. Letak geografis perairan Pulau Semak Daun berada pada $106^{\circ} 20^{\prime} 00^{\prime \prime}$ Bujur Timur (BT) sampai $106^{\circ} 57^{\prime} 00^{\prime \prime}$ Bujur Timur dan $5^{\circ} 10^{\prime} 00^{\prime}$ Lintang Selatan hingga $5^{\circ} 57^{\prime} 00^{\prime \prime}$ Lintang Selatan (Gambar 1).

Perairan dangkal Semak Daun memiliki luas 315.19 ha. Kawasan perairan dangkal tersebut terdiri atas lima goba seluas 33.30 ha dan reeflat seluas 281.89 ha. Kawasan perairan potensial seluas 2 ha dapat digunakan untuk sistem sekat (enclosure), 9.99 ha untuk keramba jaring apung/KJA (cage culture), 40.70 ha untuk sistem kandang (pen culture), dan 262.31 untuk long line. Sementara itu, kawasan perairan potensial untuk sea ranching meliputi semua kawasan, selain kawasan untuk sistem sekat dan sistem kandang (BAPEKAB 2004).

Penelitian ini ditetapkan lima titik sebagai lokasi pengamatan dalam melihat parameter kualitas air di perairan Pulau Semak Daun (Tabel 1).

\section{Jenis dan sumber data}

Penelitian ini menggunakan data primer dan data sekunder. Pengumpulan data primer dilakukan dengan dengan pengukuran dan pengamatan langsung di lapangan. Data primer yaitu kondisi kualitas perairan dari parameter fisika maupun kimia perairan di perairan Pulau Semak Daun. Data sekunder dapat disesuaikan dengan kebutuhan penelitian yang diperoleh dari beberapa kajian sebelumnya.

\section{Analisis data}

Pendugaan kuantitatif limbah berasal dari kegiatan budidaya ikan (internal loading)

Jumlah limbah yang masuk ke perairan dari kegiatan budidaya ikan kerapu diduga dari feses ikan dan dari sisa pakan yang tidak termakan. Dugaan total bahan organik yang masuk ke perairan dihitung menggunakan metode yang dikemukakan oleh Iwama (1991) dengan mengacu pada total pakan yang tidak dikonsumsi serta 
jumlah feses ikan dalam hal ini yaitu ikan kerapu, dengan persamaan sebagai berikut:

$$
\mathrm{O}=T U+T F W
$$

Keterangan:

$\mathrm{O}=$ total output bahan organik

$T U=$ total pakan yang tidak dikonsumsi dari ikan kerapu $(\mathrm{kg})$

$T F W=$ total limbah feses ikan kerapu $(\mathrm{kg})$

Pendugaan dalam kuantifikasi dari total limbah $\mathrm{N}$ berdasarkan atas data kandungan $\mathrm{N}$ dalam pakan, dan dalam karkas ikan kerapu (Barg 1992). Pendugaan total $\mathrm{N}$ mengacu dari metode Ackefors dan Enell (1990) in Barg (1992), persamaan untuk menghitung Loading $\mathrm{N}$ dan $\mathrm{P}$ adalah:

$$
K g N=(A \times C d n)-(B \times C f n)
$$

Keterangan:

$A=$ bobot basah pakan yang digunakan $(\mathrm{kg})$ $B=$ bobot basah kerapu yang diproduksi (kg) $C d=$ kandungan posfor (Cdp) dan nitrogen (Cdn) pada pakan diekspresikan sebagai \% dari bobot basah

$C f=$ kandungan posfor (Cfp) dan nitrogen (Cfn) dari karkas ikan diekspresikan sebagai $\%$ dari bobot basah

Pendugaan kuantitatif limbah berasal dari daratan (antropogenik) (external loading)

Pendugaan beban limbah yang berasal dari daratan atau dari kegiatan masyarakat mengacu pada metode yang dikembangkan oleh Rachmansyah (2004). Pendugaan kuantitatif limbah yang berasal dari daratan yaitu dari aktivitas pemukiman yang bertujuan untuk menghitung besaran potensi kontribusi beban limbah organik (nitrogen) ke perairan.

Besaran limbah organik (total N) dari wilayah pemukiman dapat diketahui dengan cara menghitung langsung berdasarkan jumlah penduduk yang bermukim atau bertempat tinggal di wilayah tersebut, dalam hal ini masyarakat yang berada di sekitar perairan Pulau Semak Daun. Besaran kontribusi limbah yaitu terdiri atas limbah padat (kg/hari) serta limbah cair (liter/ hari) yang berasal dari penduduk dikalikan dengan koefisien limbah yang didapatkan dari berbagai acuan (Tabel 2), antara lain 1) Sogreah (1974); 2) World Bank (1993), vide Rachmansyah (2004).

Beban limbah yang berasal dari pemukiman diperoleh dari data penghitungan secara langsung dari lokasi pengamatan yang mengacu pada data sekunder. Pendugaan total nitrogen (TN) dari limbah antropogenik dapat dihitung dengan mengalikan antara tingkat aktivitas kegiatan dengan koefisien limbah (N). Persamaannya sebagai berikut:

$$
T N=\text { tingkat aktivitas } \times \text { koefisien limbah }
$$

Perhitungan pendugaan daya dukung melalui pendekatan beban limbah $N$ (NH3-N)

Kadar nitrogen yang dihasilkan dari kegiatan aktivitas budidaya menyebabkan terjadinya suatu pengkayaan nutrien di perairan. Tinggi rendahnya kadar nutrien di perairan menurut (Gowen et al. 1989 vide Barg 1992) ditentukan oleh beberapa faktor yaitu volume badan air, laju pembilasan, dan fluktuasi pasang surut. Adapun persamaannya sebagai berikut :

$$
\mathrm{Ec}=\frac{N x F}{V}
$$

Keterangan:

$\mathrm{Ec}=$ konsentrasi limbah $(\mathrm{mg} / \mathrm{l})$

$N=$ output harian dari limbah nitrogen terlarut (gram)

$F=$ flushing time dari badan air

$V=$ volume badan air (m3)

Flushing time $(\mathrm{F})$ yaitu waktu (jumlah hari) yang diperlukan limbah berdiam (tinggal) dalam badan air sehingga lingkungan perairan menjadi bersih. Penentuan flushing time ditentukan dengan menggunakan formula:

$$
F=\frac{1}{D} ; D=\left(\frac{V_{h}-V_{i}}{T \times V_{h}}\right)
$$

Keterangan:

$\mathrm{F}=$ flushing time

$\mathrm{D}=$ laju pengenceran

$\mathrm{Vh}-\mathrm{Vi}=$ volume pergantian pasang $\left(\mathrm{m}^{3}\right)$

$\mathrm{Vh}=$ volume air dalam badan air saat pasang tertinggi $\left(\mathrm{m}^{3}\right)$

$\mathrm{Vi}=$ volume air dalam badan air saat surut $\left(\mathrm{m}^{3}\right)$

$\mathrm{T}=$ periode pasang dalam satuan hari

Perhitungan diukur pada saat pasang tertinggi MHWS (Mean High Water Spring), dan pada saat surut terendah MLWS (Mean Low Water Spring) dengan menggunakan persamaan sebagai berikut: 


$$
\mathrm{V}_{\mathrm{h}}=\mathrm{A} \times \mathrm{h}_{1} \text { dan } \mathrm{V}_{\mathrm{i}}=\mathrm{A} \times \mathrm{h}_{0}
$$

Keterangan:

$\mathrm{A}=$ luas perairan dangkal Pulau Semak Daun (315.19 Ha)

$\mathrm{h}_{1}$ dan $\mathrm{h}_{0}=$ kedalaman perairan saat pasang tertinggi dan surut terendah

$\mathrm{Vh}=$ volume air pada saat pasang tertinggi $\left(\mathrm{m}^{3}\right)$

$\mathrm{Vi}=$ volume air pada saat surut terendah $\left(\mathrm{m}^{3}\right)$

$\mathrm{Vh}-\mathrm{Vi}=$ perubahan volume karena efek pasang surut

\section{Beban pencemaran}

Perhitungan selanjutnya adalah menganalisis beban pencemaran yang dihasilkan dari beban limbah pakan dan dari daratan yang masuk ke perairan Pulau Semak Daun. Cara perhitungan beban pencemaran berdasarkan atas pengukuran debit air dan konsentrasi limbah yang dihasilkan dari pakan dan daratan dengan persamaan (Mitsch \& Goesselink 1993 vide Marganof 2007).

$$
\mathrm{BP}=\mathrm{Q} \times \mathrm{C}
$$

Keterangan :

$\mathrm{BP}=$ beban pencemaran

$\mathrm{Q}=$ volume $\operatorname{air}\left(\mathrm{m}^{3}\right)$
$\mathrm{C}=$ konsentrasi limbah $\mathrm{N}(\mathrm{mg} / \mathrm{l})$

Konsentrasi limbah yang diteliti terdapat dua nilai konsentrasi yang berbeda, yaitu dari konsentrasi yang masuk ke perairan dan konsentrasi yang sudah ada. Oleh karena itu untuk mengetahui total konsentrasi limbah yang masuk ke perairan, dilakukan dengan model perhitungan sebagai berikut:

$$
\mathrm{Q}_{3} \cdot \mathrm{C}_{3}=\mathrm{Q}_{1} \cdot \mathrm{C}_{1}+\mathrm{Q}_{2} \cdot \mathrm{C}_{2}
$$

Berdasarkan model perhitungan diatas, maka didapatkan nilai total konsentrasi limbah yang masuk ke perairan (C3) sebagai berikut:

$$
Q_{3}=\frac{Q_{1} \cdot C_{1}+Q_{2} \cdot C_{2}}{Q_{3}}
$$

Keterangan :

$C_{1}=$ konsentrasi limbah $\mathrm{N}$ yang masuk (mg/l)

$\mathrm{C}_{2}=$ konsentrasi limbah $\mathrm{N}$ di lokasi $(\mathrm{mg} / \mathrm{l})$

$\mathrm{C}_{3}=$ total nilai konsentrasi $\mathrm{N}(\mathrm{mg} / \mathrm{l})$

$Q_{1}=$ volume air masuk $\left(\mathrm{m}^{3}\right)$

$Q_{2}=$ volume air pada saat di lokasi $\left(\mathrm{m}^{3}\right)$

$Q_{3}=$ volume air total $\left(\mathrm{m}^{3}\right)$

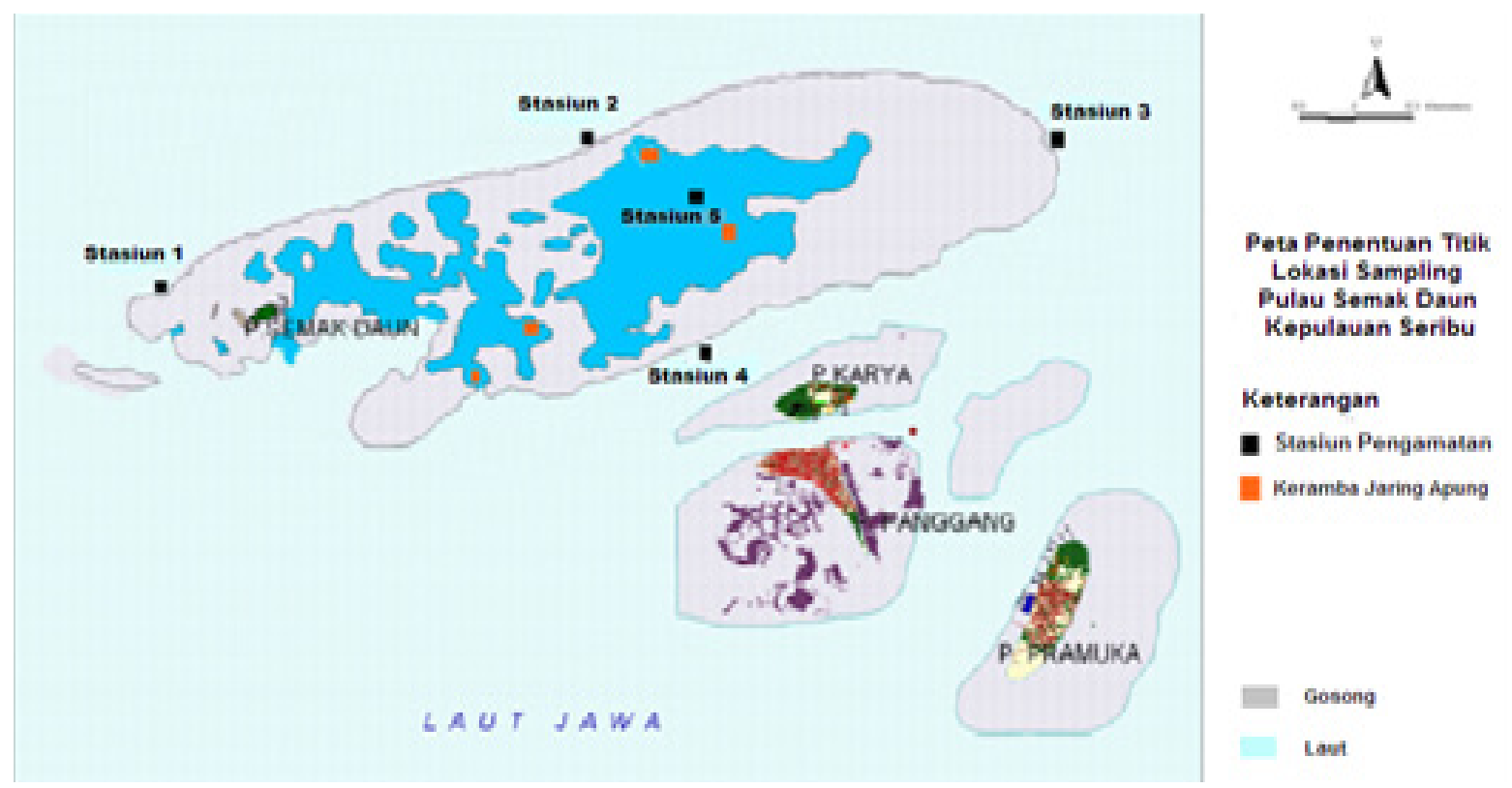

Gambar 1. Lokasi penelitian 
Tabel 1. Lokasi koordinat stasiun pengamatan perairan Pulau Semak Daun

\begin{tabular}{|c|c|c|}
\hline Titik Pengamatan/Stasiun & Posisi geografis & Keterangan \\
\hline Sisi Barat Perairan Pulau Semak Daun & $\begin{array}{l}\text { 106'33'980”BT } \\
\text { 05'43'627’LS }\end{array}$ & Stasiun 1 \\
\hline Sisi Utara Perairan Pulau Semak Daun & $\begin{array}{l}\text { 106 36’215”BT } \\
05^{\circ} 42^{\prime} 933 \text { ”SS }\end{array}$ & Stasiun 2 \\
\hline Sisi Timur Perairan Pulau Semak Daun & $\begin{array}{l}106^{\circ} 36^{\prime} 744^{\prime \prime} \mathrm{BT} \\
05^{\circ} 43^{\prime} 515^{\prime \prime} \mathrm{LS}\end{array}$ & Stasiun 3 \\
\hline Sisi Selatan Perairan Pulau Semak Daun & $\begin{array}{l}106^{\circ} 35^{\prime} 530^{\prime \prime} \mathrm{BT} \\
05^{\circ} 43^{\prime 2} 239^{\prime \prime} \mathrm{LS}\end{array}$ & Stasiun 4 \\
\hline Sisi dalam/tengahPerairan Pulau Semak Daun & $\begin{array}{l}\text { 106 } 36^{\circ} 046^{\prime \prime} \mathrm{BT} \\
05^{\circ} 43^{\prime} 741^{\prime \prime} \mathrm{LS}\end{array}$ & Stasiun 5 \\
\hline
\end{tabular}

Tabel 2. Jenis aktivitas dan koefisien limbah pemukiman (sumber: 1) World Bank (1993) vide Rachmansyah (2004)

\begin{tabular}{llc}
\hline No & \multicolumn{1}{c}{ Jenis limbah } & Koefisien Limbah \\
\hline & & \\
1 & Limbah Padat & $1.86 \mathrm{~kg}$ N $/$ Org $/$ Tahun $^{1}$ \\
2 & Sampah & $4 \mathrm{~kg} \mathrm{~N} /$ Org $/$ Tahun $^{2}$ \\
\hline
\end{tabular}

\section{HASIL DAN PEMBAHASAN}

\section{Kondisi umum perairan Pulau Semak Daun}

Pulau Semak Daun merupakan salah satu pulau yang terdapat di wilayah administrasi Kelurahan Pulau Panggang. Pulau Semak Daun memliki luas daratan dan karang. Luas daratan dari Pulau Semak Daun sendiri yaitu sekitar 0,50 ha dengan luas karang mencapai 315,19 ha (Kurnia 2012 vide Purnomo 2013). Pulau Semak Daun mempunyai potensi yang cukup besar sebagai kawasan marineculture, karena memiliki wilayah perairan dangkal dan terlindung yang cukup luas.

Kondisi angin yang terjadi di wilayah Kepulauan Seribu dipengaruhi dari angin musim, yang terbagi menjadi dua yaitu angin musim barat (Desember-Maret) dan angin musim timur (Juni-September) serta adanya musim peralihan (pancaroba) yang terjadi diantara bulan April-Mei dan Oktober-November. Kondisi angin pada musim barat memiliki kecepatan yang cukup bervariasi antara 7-20 knot per jam, sedangkan pada musim timur kecepatan angin berkisar antara 7-15 knot per jam.

\section{Kondisi fisika dan kimia perairan Pulau Semak Daun}

Hasil pengukuran parameter fisika dan kimia perairan Pulau Semak Daun di lima lokasi pengamatan yang telah ditentukan, ditampilkan pada Tabel 3. Berdasarkan hasil pengukuran dapat dikatakan bahwa kondisi atau kualitas perairan di Pulau Semak Daun jika dibandingkan dengan baku mutu yang dikeluarkan oleh Kep.Men LH No 51 tahun 2004 masih dalam kategori baik. Tetapi, terdapat satu parameter yang mengalami perbedaan, yaitu nitrat. Kadar nitrat mengalami peningkatan lebih dari $0.20 \mathrm{mg} / 1$ berpotensi untuk menyebabkan terjadinya eutrofikasi dan selanjutnya akan memicu pertumbuhan alga dan tumbuhan air secara pesat.

\section{Pendugaan kuantitatif limbah berasal dari kegiatan budidaya ikan (internal loading)}

Estimasi pendugaan yang digunakan dalam studi ini menggunakan acuan oleh peneliti sebelumnya yaitu Noor (2009) dan merupakan estimasi pengembangan formula dari kondisi beban pakan yang masuk ke perairan. Hasil penghitungan terhadap pendugaan total $\mathrm{N}$ dari kegiatan keramba jaring apung yang telah dilakukan yaitu produksi total ikan $300 \mathrm{~kg}$, dengan nilai rasio konversi pakan rucah untuk ikan kerapu yaitu (FCR) 6.00 (Sih-Yang Sim et al. 2005 vide Akbar et al. 2012) maka membutuhkan pakan rucah sebanyak 1800 kg. Berdasarkan hasil analisis proximat, 
kandungan $\mathrm{N}(12.6 \%)$ yang terdapat pada ikan rucah yaitu $226.80 \mathrm{~kg}$. Pakan yang habis dimakan (82\%) yaitu sebanyak 1476 kg dengan kandungan $\mathrm{N}(12.6 \%)$ sebanyak $185.98 \mathrm{~kg}$, sedangkan pakan yang tidak habis dimakan atau pakan yang terbuang yaitu sebanyak $324 \mathrm{~kg}$ dengan kandungan $\mathrm{N}$ sebanyak $40.82 \mathrm{~kg}$.

Besaran jumlah feses yang telah dikeluarkan sebanyak $581.54 \mathrm{~kg}$. Besaran jumlah feses yaitu $(39.40 \%)$ dari total pakan yang habis dimakan, dengan kadar $\mathrm{N}$ dalam feses sebanyak $35.34 \mathrm{~kg}$. kadar $\mathrm{N}$ dalam feses didapat dari $\mathrm{N}$ yang berada pada pakan yang habis dimakan, dikurangi dengan kadar $\mathrm{N}$ dari tingkat kecernaan pakan yang habis dimakan. Selain keluar berubah menjadi feses, $\mathrm{N}$ juga akan terbuang sebagai ekskresi. Adapun nilai ekskresi didapat dari tingkat kecernaan $\mathrm{N}$ terhadap pakan dikurangi dengan Nilai $\mathrm{N}$ yang tersimpan dalam daging ikan (retensi). Nilai ekskresi N yang dikeluarkan ikan sebanyak $111.32 \mathrm{~kg}$ $\mathrm{N}$. Sehingga jumlah loading $\mathrm{N}$ ke perairan yang berasal dari kegiatan budidaya keramba jaring apung yaitu sebesar $187.48 \mathrm{~kg}$ N/6 bulan/unit (Tabel 4). Apabila dikonversikan dalam harian nilai $\mathrm{N}$ yaitu $1.04 \mathrm{~kg} /$ hari.

\section{Pendugaan kuantitatif limbah berasal dari daratan (antropogenik) (external loading)}

Hasil perhitungan pendugaan (Tabel 5), dampak dari aktivitas masyarakat (Kegiatan Rumah Tangga) memiliki kontribusi yang cukup besar. Berdasarkan data demografi di Kelurahan Pulau Panggang pada tahun 2010 menurut BPS Provinsi DKI Jakarta, jumlah penduduknya yaitu sebesar 5123 jiwa dengan komposisi penduduk 2613 berkelamin laki-laki dan 2510 yang berkelamin perempuan. Berdasarkan hasil perhitungan pendugaan didapatkan hasil data bahwa jumlah kadar total N yaitu sebesar $30020.78 \mathrm{~kg} /$ tahun. Berdasarkan hasil asumsi bahwa sekitar 25\% dari total limbah yang masuk ke perairan setelah terjadinya proses di daratan, maka kontribusi limbah ke perairan dari kegiatan antropogenik adalah $0.25 \mathrm{x}$ $30020.78=7505.20 \mathrm{~kg} \mathrm{~N}$ per tahun. Apabila dikonversikan secara harian dalam jangka waktu satu tahun yaitu sebesar $20.56 \mathrm{~kg}$ $\mathrm{N} /$ hari. Besaran total $\mathrm{N}$ selama proses masa pemeliharaan ikan yang berlangsung sekitar 180 hari, maka besaran limbah dari kegiatan antropogenik yaitu $3700.80 \mathrm{~kg} \mathrm{~N}$ dan $1497.60 \mathrm{~kg}$ P.

\section{Pendugaan daya dukung melalui pendekatan beban limbah $\mathbf{N}$ (NH3- N)}

Daya dukung lingkungan perairan dijelaskan yaitu sebagai suatu yang saling berhubungan dengan kondisi produktivitas lestari perairan. Daya dukung lingkungan sebagaimana dijelaskan oleh Clark (1974) dan Poernomo (1997) adalah nilai suatu mutu lingkungan yang ditimbulkan akibat interaksi dari semua komponen (fisika, kimia, dan biologi) dalam satu ekosistem dan dapat mengalami perubahan akibat kerusakan yang ditimbulkan oleh manusia yang dapat mengurangi suplai atau penggunaan energi. Apabila diterapkan sebagai daya dukung lingkungan pesisir yaitu kemampuan badan air atau kawasan pesisir dalam menerima beban limbah.

Kemampuan perairan dalam menerima beban limbah sangat dipengaruhi dari laju pengenceran (flushing time), volume air serta beban limbah yang masuk ke dalam perairan (Gowen et al. 1989 vide Barg 1992). Flushing time diartikan yaitu waktu yang dibutuhkan dari satu unit volume massa air tinggal dalam suatu area tertentu sebelum digantikan oleh unit volume massa air yang baru.

Estimasi daya dukung dari lingkungan perairan akan dapat diketahui pula ukuran seberapa banyak ikan untuk kegiatan budidaya yang dapat ditanam didalam luasan yang sudah ditentukan sehingga tidak menimbulkan adanya perubahan lingkungan dan ekosistem disekitarnya. Beberapa parameter yang dapat dijadikan acuan dalam menghitung pendugaan daya dukung selama 6 bulan (Tabel 6).

Pendugaan daya dukung dengan pendekatan beban limbah $\mathrm{N}$ di perairan pulau Semak Daun yaitu berdasarkan kepada beban limbah yang berasal dari kegiatan budidaya KJA serta beban limbah yang berasal dari aktivitas antropogenik di daratan. Berdasarkan hasil dengan menggunakan formula yang dikembangkan oleh Barg (1992), untuk menghitung nutrient loading $\mathrm{N}$, hasil yang diperoleh bahwa tingkat konsentrasi $\mathrm{N}$ (C1) yang masuk ke perairan adalah $0.01 \mathrm{mg} / 1$. Nilai $\mathrm{N}$ merupakan nilai $\mathrm{N}$ dalam ammonia (NH3-N) dari total limbah hasil produksi KJA dan hasil dari kegiatan antropogenik di daratan dan dihubungkan dengan nilai $\mathrm{N}$ pada baku mutu perairan untuk kegiatan budidaya (Kementerian Lingkungan Hidup 2004). 


\section{Beban pencemaran}

Sumber dari beban pencemaran yaitu dari kegiatan keramba jaring apung (KJA) yang berupa sisa pakan tidak dimakan dan feses ikan serta dari kegiatan antropogenik di sekitar perairan Pulau Semak Daun. Konsentrasi limbah yang diteliti terdapat dua nilai konsentrasi yang berbeda, yaitu dari konsentrasi yang masuk ke perairan dengan konsentrasi yang sudah ada. Berdasarkan hasil penghitungan, nilai konsentrasi total limbah N (C3) adalah 0.01 mg/1 yang disajikan pada Gambar 2 .

Pada Gambar 2, diketahui bahwa nilai untuk daya dukung perairan adalah sebesar $0.27 \mathrm{mg} / 1$ yang didapatkan dari selisih antara nilai baku mutu perairan dengan nilai total konsentrasi $\mathrm{NH}_{3} \mathrm{~N}$ dari limbah N. Kemudian untuk mengetahui seberapa banyak perairan dapat menampung jumlah unit produksi, dilakukan penghitungan dengan cara membagi nilai daya dukung perairan $(0.27 \mathrm{mg} / 1)$ dengan nilai konsentrasi $\mathrm{N}$ (0.01 mg/l) yang masuk ke perairan. Dari penghitungan tersebut didapatkan jumlah unit keramba jaring apung yang dapat ditampung adalah 94 unit. Jika dalam satu unit menghasilkan $300 \mathrm{~kg}$ ikan, maka didapatkan produksi ikan yang dapat ditampung yaitu sebesar 28.20 ton ikan. Hitungan ini berdasarkan nilai daya dukung melalui pendekatan beban limbah $\mathrm{N}$.

Tabel 3. Hasil pengukuran parameter fisika dan kimia perairan

\begin{tabular}{llcccccc}
\hline \multirow{2}{*}{ Parameter } & Satuan & \multicolumn{7}{c}{ Stasiun } & Baku Mutu \\
\cline { 3 - 6 } & & 1 & 2 & 3 & 4 & 5 & Air Laut $^{1}$ \\
\hline Fisika & & & & & & & \\
Suhu & ${ }^{\circ} \mathrm{C}$ & 29.50 & 29.80 & 29.70 & 29.70 & 30.20 & $28-32$ \\
Salinitas & $\%$ oo & 30.60 & 31.20 & 31.20 & 32.20 & 31.60 & $33-34$ \\
Kecerahan & $\mathrm{M}$ & 9.40 & 5.60 & 8.20 & 7.40 & 6.60 & $>5$ \\
Kekeruhan & $\mathrm{NTU}$ & 0.45 & 0.40 & 0.57 & 0.37 & 0.87 & $<5$ \\
Kecepatan Arus & $\mathrm{cm} /$ detik & 0.16 & 0.15 & 0.45 & 0.38 & 0.09 & $0.15-0.25$ \\
Kimia & & & & & & & \\
pH & - & 8.01 & 8.11 & 8.04 & 8.02 & 8.00 & $7-8.50$ \\
Nitrat & $\mathrm{mg} / 1$ & 0.136 & 0.364 & 0.216 & 0.187 & 0.033 & 0.008 \\
Nitrit & $\mathrm{mg} / 1$ & $<0.004$ & $<0.004$ & $<0.004$ & $<0.004$ & $<0.004$ & - \\
Ammonia & $\mathrm{mg} / 1$ & 0.067 & 0.04 & 0.046 & 0.052 & 0.028 & 0.30 \\
Fosfat & $\mathrm{mg} / 1$ & $<0.002$ & $<0.002$ & $<0.002$ & $<0.002$ & $<0.002$ & 0.015 \\
DO & $\mathrm{mg} / 1$ & 6.73 & 6.50 & 6.83 & 6.23 & 6.33 & $>5$ \\
\hline
\end{tabular}

Tabel 4. Nilai Hasil Pendugaan Total N Pakan Selama 6 bulan/unit

\begin{tabular}{clcl}
\hline No & \multicolumn{1}{c}{ Parameter } & Nilai & Total (Kg)/6 Bulan/Unit \\
\hline 1 & Rasio konversi pakan (FCR) & 6.00 & - \\
2 & Pakan yang diberikan & - & 1800 \\
& Kandungan N dalam pakan (\%) & 12.60 & 226.80 \\
3 & $\begin{array}{l}\text { Pakan habis dimakan (\%) } \\
\text { Kandungan N dalam pakan yang }\end{array}$ & 12.60 & 1476 \\
& habis (\%) \\
4 & Pakan terbuang (\%) & 185.98 \\
& Kandungan N pakan terbuang (\%) & 12.60 & 324 \\
5 & $\begin{array}{l}\text { Tingkat kecernaan N dalam } \\
\text { pakan (\%) }\end{array}$ & 81 & 150.62 \\
\hline
\end{tabular}


Lanjutan Tabel 4. Nilai Hasil Pendugaan Total N Pakan Selama 6 bulan/unit

\begin{tabular}{clcl}
\hline No & \multicolumn{1}{c}{ Parameter } & Nilai & Total (Kg)/6 Bulan/Unit \\
\hline 6 & Jumlah feses yang keluar (\%) & 39.40 & 581.54 \\
& Nilai N dalam feses & - & 35.34 \\
7 & Nilai retensi dari N (\%) & 26.10 & 39.32 \\
8 & Nilai ekskresi dari N & - & 111.32 \\
9 & Total loading N (N pakan sisa + & - & 187.48 \\
& N feses + N ekskresi) & & \\
\hline
\end{tabular}

Tabel 5. Pendugaan beban limbah antropogenik sekitar perairan Pulau Semak Daun

\begin{tabular}{lcll}
\hline Jenis limbah & Koefisien Limbah & $\begin{array}{c}\mathrm{T} \text { i } \mathrm{n} \mathrm{g} \mathrm{k} \mathrm{a} \mathrm{t} \\
\text { Aktivitas }\end{array}$ & Total N (Kg/Tahun) \\
\hline & & & \\
1. Limbah Padat & $1.86 \mathrm{Kg} \mathrm{N} / \mathrm{Org} / \mathrm{Thn}^{1}$ & 5123 orang $^{3}$ & 9528.78 \\
2. Sampah & $4 \mathrm{Kg} \mathrm{N} / \mathrm{Org} / \mathrm{Thn}^{2}$ & & 20492 \\
Jumlah & & 30020.78 \\
\hline
\end{tabular}

Tabel 6. Penghitungan daya dukung melalui pendekatan beban limbah $\mathrm{N}$

\begin{tabular}{|c|c|c|c|}
\hline No & Parameter & Nilai & Satuan \\
\hline 1 & Luas Perairan & 315.19 & $\mathrm{Ha}$ \\
\hline 2 & Volume air pasang tertinggi & 3467090 & $\mathrm{~m} 3$ \\
\hline 3 & Volume air surut terendah & 1260760 & $\mathrm{~m} 3$ \\
\hline 4 & Volume rata-rata perairan & 2660729 & $\mathrm{~m} 3$ \\
\hline 5 & Flushing time & 0.40 & hari \\
\hline 6 & $\begin{array}{l}\text { Beban limbah budidaya } \\
\text { - pakan terbuang } \\
\text { - feses } \\
\text { - } \quad \text { ekskresi }\end{array}$ & $\begin{array}{l}0.227 \\
0.196 \\
0.618\end{array}$ & $\begin{array}{l}\mathrm{Kg} / \text { hari } \\
\mathrm{Kg} / \text { hari } \\
\mathrm{Kg} / \text { hari }\end{array}$ \\
\hline 7 & $\begin{array}{l}\text { Limbah antropogenik } \\
\text { Total beban limbah }\end{array}$ & $\begin{array}{l}20.56 \\
21.60\end{array}$ & $\begin{array}{l}\mathrm{Kg} / \text { hari } \\
\mathrm{Kg} / \text { hari }\end{array}$ \\
\hline 8 & Konsentrasi $\mathrm{NH}$ dari Limbah $\mathrm{N}\left(\mathrm{C}_{1}\right)$ & 0.0029 & $\mathrm{mg} / 1$ \\
\hline 9 & Konsentrasi $\mathrm{NH}$ di lokasi $\left(\mathrm{C}_{2}\right)$ & 0.0466 & $\mathrm{mg} / 1$ \\
\hline 10 & Total Konsentrasi $\left(\mathrm{C}_{3}\right)$ & 0.027 & $\mathrm{mg} / 1$ \\
\hline 11 & Baku mutu $\mathrm{NH}_{3}{ }^{*}$ & 0.30 & $\mathrm{mg} / 1$ \\
\hline 12 & Daya tampung & 0.273 & $\mathrm{mg} / 1$ \\
\hline 13 & $\begin{array}{l}\text { Jumlah keramba yang dapat digu- } \\
\text { nakan }\end{array}$ & 94 & unit \\
\hline 14 & Jumlah Ikan yang dapat ditampung & 28241 & Kg ikan \\
\hline
\end{tabular}




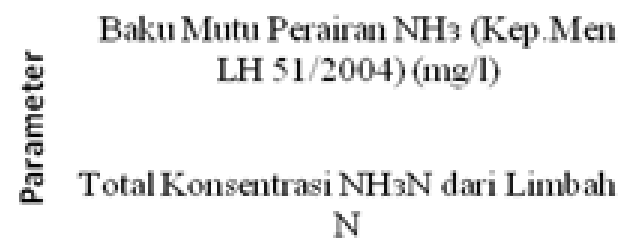

\begin{tabular}{|c|c|c|}
\hline & $\mathrm{mg} / \mathrm{l}$ & 0.25 \\
\hline & $\begin{array}{c}\text { Total Konsentrasi NH3N dari Limbah } \\
\mathrm{N}\end{array}$ & $\begin{array}{c}\text { Baku Mutu Perairan NH3 (Kep.Men } \\
\text { LH 51/2004)(mg/) }\end{array}$ \\
\hline = Nilai Konsentrasi (mg/) & 0.027 & 0.3 \\
\hline = Daya Tampung (mg/l) & 0.273 & \\
\hline
\end{tabular}

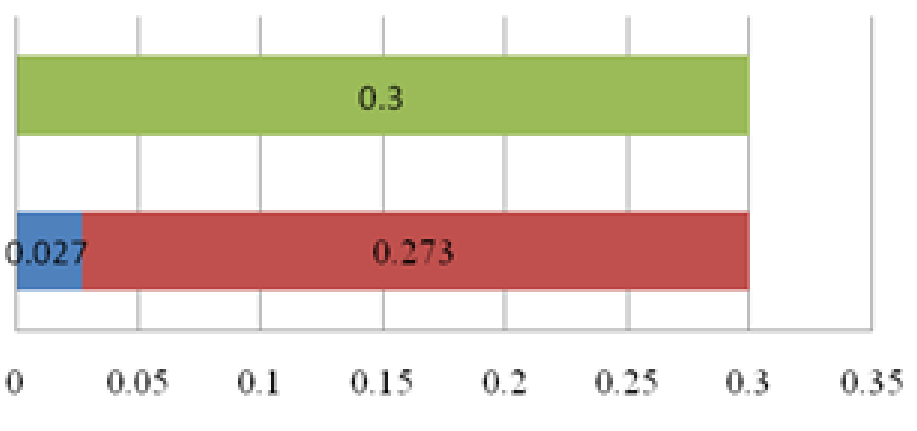

Gambar 2. Daya tampung perairan berdasarkan nilai baku mutu perairan

\section{KESIMPULAN}

Data hasil penelitian mengenai analisis daya dukung dengan pendekatan beban limbah $N$, perairan Pulau Semak Daun mampu menampung 94 unit atau 28.2 ton ikan dari kegiatan keramba jaring apung. Jumlah tersebut merupakan jumlah optimal yang diharapkan dalam kegiatan budidaya, sehingga beban limbah organik yang masuk tidak mengganggu ekosistem perairan lainnya.

\section{DAFTAR PUSTAKA}

Akbar S. Marsoedi, Soemarno, Kusnendar E. 2012. Pengaruh pemberian pakan yang berbeda terhadap pertumbuhan ikan kerapu macan (Ephinephelus fuscoguttatus) pada fase pendederan di keramba jaring apung (KJA). Jurnal Teknologi Pangan. Vol 1:93-101

[BAPEKAB] Badan Perencanaan Kabupaten Pemerintah Kabupaten Administrasi Kepulauan Seribu dan PT Plarenco. 2004. Kajian Pengembangan SeaFarming diKabupaten Administrasi Kepulauan Seribu [Laporan Akhir].

Barg UC. 1992. Guidelines of the promotion of environmental management of coastal aquaculture development. FAO Fisheries Technical Paper 328, Rome.

Bengen DG. 2001. Ekosistem dan sumberdaya pesisir dan laut serta pengelolaan secara terpadu dan berkelanjutan. Prosiding pelatihan pengelolaan pesisir dan terpadu. Bogor. Hlm 28-55

[BPS] Badan Pusat Statistik Kabupaten Administrasi Kepulauan Seribu,
2010. Kepulauan Seribu Dalam Angka 2010. Katalog Badan Pusat Statisitik. Jakarta (ID)

Clark J. 1974. Coastal Ecosystems: Ecological considerations for management of the coastal zone. The Conservation Foundation. Washington DC.

Iwama GK. 1991. Interactions between aquaculture and the environment. Critical Reviews in Environtmental Control. Vol 21(2): 177-216.

Marganof, Darusman LK, Riani E, Pramudya B. 2007. Analisis beban pencemaran, kapasitas asimilasi dan tingkat pencemaran dalam upaya pengendalian pencemaran perairan Danau Maninjau. Jurnal Perikanan dan Kelautan Vol 12: 8-14

Napitupulu DL, Hodijah SN, Nugroho AC. 2005. Socio-economic assessment: in the user of reef resources by local community and other direct stakeholders. A research report. TERANGI. Jakarta: $140 \mathrm{hlm}$

Noor A. 2009. Model pengelolaan kualitas lingkungan berbasis daya dukung (carrying capacity) perairan teluk bagi pengembangan budidaya keramba jaring apung ikan kerapu (studi kasus di Teluk Tamiang, Kabupaten Kotabaru, Propinsi Kalimantan Selatan. [Disertasi]. Bogor : Institut Pertanian Bogor.

[PKSPL] Pusat Kajian Sumberdaya Pesisir dan Lautan, Institut Pertanian Bogor. 2006. Konsep Pengembangan Sea Farming di Kabupaten Administrasi Kepulauan Seribu, Provinsi DKI Jakarta. Working Paper PKSPLIPB, Direktorat Jenderal Perikanan 
Budidaya, Departemen Kelautan dan Perikanan. Jakarta, disampaikan pada 12 Oktober 2006.

Poernomo A. 1997. Petunjuk Pelaksanaan Pengembangan Budidaya Udang Ramah Lingkungan. Ditjend Perikanan, Jakarta

Purnomo T. Hariyadi S. Yonvitner. 2013. Kajian Potensi Perairan Dangkal untuk Pengembangan Wisata Bahari dan Dampak Pemanfaatannya Bagi Masyarakat Sekitar (studi kasus Pulau Semak Daun sebagai daerah penunjang kegiatan wisata Pulau Pramuka Kabupaten Administrasi Kepulauan Seribu). Depik, 2(3): 172183. Desember 2013.ISSN 2089-7790.

Rachmansyah. 2004. Analisis daya dukung lingkungan perairan Teluk Awarange Kabupaten Barru Sulawesi Selatan bagi pengembangan budidaya bandeng dalam keramba jaring apung [Disertasi]. Bogor : Institut Pertanian Bogor.

Rudiyanto BY. 2011. Analisis kelembagaan dan biaya transaksi dan pengelolaan seafarming di Pulau panggang Kabupaten Administrasi Kepulauan Seribu [Tesis]. Bogor : Institut Pertanian Bogor

Tacon AJ. 2003. Aquaculture production and trend analysis. In: Review of the State of World Aquaculture. FAO Fishery Circular No. 886, Rev. 2, FAO. Rome, pp. 5-30

Kementrian Lingkungan Hidup (KLH). 2004. Keputusan Menteri KLH No. 51/2004 Tentang Baku Mutu Air Laut untuk Biota Laut. KLH, Jakarta 